\title{
The simulation of Antarctic sea ice in the Hadley Centre Glimate Model (HadCM3)
}

\author{
John Turner, ${ }^{1}$ William Connolley, ${ }^{1}$ Doug Cresswell, ${ }^{2}$ Steven Harangozo ${ }^{1}$ \\ ${ }^{1}$ British Antarctic Survey, Natural Environment Research Council, Madingley Road, Cambridge CB3 0ET, England \\ ${ }^{2}$ Hadley Centre for Climate Prediction and Research, Meteorological Office, London Road, Bracknell, Berkshire RG12 2SZ, England
}

\begin{abstract}
An assessment is presented of the extent and variability of Antarctic sea ice in the non-flux-corrected version of the Hadley Centre's coupled atmosphere- ${ }^{-}$-ean general circulation model (HadCM3). The results are based on a 100 year segment of a long control run of the model with the sea ice being compared to ice extents and concentrations derived from passive microwave satellite data. Over the year as a whole, the model ice extent (the area with $>15 \%$ ice concentration) is $91 \%$ of that determined from satellite imagery, but, not surprisingly, the regional-scale distribution differs from the observed. Throughout the year there is too much ice near $90^{\circ} \mathrm{E}$, which is believed to be present as a result of incorrect ocean currents near Kerguelen. In contrast to the satellite data, there is too little ice to the west of the Antarctic Peninsula as a result of anomalously northerly atmospheric flow, compared to observations. During the winter the sea-ice concentrations in the model are too high, possibly as a result of the simple representation of the sea ice, which does not simulate complex dynamical interactions within the pack. The annual cycle of sea-ice advance/retreat in the model has a phase error, with the winter sea-ice maximum extent being too late by about 1 month.
\end{abstract}

\section{INTRODUCTION}

Numerical models are one of the most important tools for understanding the present climate of the Earth and how it may evolve over the coming years. During the last few decades these models have evolved from simple atmosphereonly models, which could reproduce only the broad-scale structure of the Earth's climate, to complex, coupled atmosphere-ocean general circulation models (AOGCMs) that represent all the important elements of the climate system (including sea-ice and land processes). The Hadley Centre for Climate Prediction and Research has been developing its AOGCM for a number of years. The first model used by the Hadley Centre (Murphy, 1995) had a very simple representation of sea ice that included sea-ice thermodynamics, but no dynamics. The performance of this model was poor in the Antarctic: even with flux correction, almost all of the Antarctic sea ice had disappeared after 70 years of a control integration. The second version of the Hadley Centre's model (HadCM2) (Johns and others, 1997) used the zero-layer thermodynamics of Semtner (1976), combined with the leads formulation of Hibler (1979), with the sea-ice dynamics parameterized using the technique of Bryan (1969), which advects ice with the top-layer ocean current. Version 3 of the model (HadCM3) is a further development of the AOGCM that does not include flux correction. The model has been used in a number of investigations into climate processes (Wood and others, 1999) and possible future-climate scenarios. In the high-latitude areas of both hemispheres the simulation of sea ice is extremely important since the ice provides a very effective cap to the upper level of the ocean, severely reducing the fluxes of sensible and latent heat from the surface into the atmosphere (Maykut, 1978).
Runs of GCMs that have removed large amounts of Antarctic winter sea ice have resulted in warming of the lowest layers of the Antarctic atmosphere and a reduction in the westerlies (Mitchell and Hills, 1986). It is therefore essential to have a good simulation of sea ice in climate models and to include the complex interactions and feedbacks that are known to occur between the sea ice, the ocean and atmosphere. These should include the opening up of leads, rafting of the sea ice and dealing with the effects of a snow layer on top of the ice.

These models are primarily designed for use in climatechange prediction. An important aspect of the model design is to ensure there is a matching level of complexity in each of the model's components. One of the major differences between HadCM3 and earlier Hadley Centre models is an increase in the ocean resolution, with six ocean gridboxes to each atmospheric gridbox. Along with other changes to the model, this much improved the simulation of ocean heat transports (Gordon and others, 2000). The sea-ice model was not changed, and here we consider the ability of the relatively simple representation of sea-ice processes to simulate the distribution of Antarctic sea ice. We identify a number of areas where the model inadequately reproduces observed sea-ice distributions and consider possible causes. The importance of the deficiencies to the overall simulation of climate is not considered in detail, as this would require sensitivity studies with the model, which are beyond the scope of this study.

The goal of this paper is to assess the simulation of Antarctic sea ice in the HadCM3 AOGCM against the best observational datasets produced from satellite passive microwave instruments. The variability of the sea ice throughout the year is examined on Antarctic-wide and regional scales (Fig. 1). Using model diagnostics and climatological fields we investigate causes for the model deficiencies. 


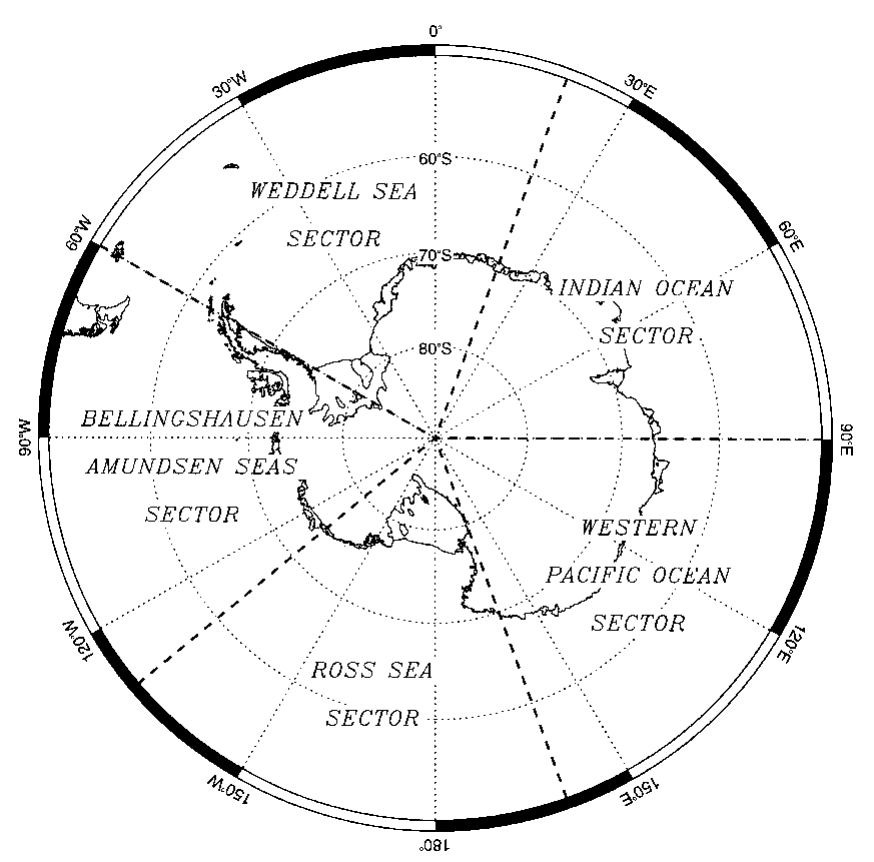

Fig. 1. A map of the Antarctic showing the five sectors that are used in the regional sea-ice analysis.

The results presented here are based on a 100 year segment of a long control run of the AOGGM that attempted to simulate the pre-industrial climate; the problems of validating a pre-industrial control run against modern-day observations are discussed in Gordon and others (2000). From this 400 year run mean sea-ice extent and concentration data were available for each month, and 100 years of information were used to produce the long-term means used here.

In section 2 we describe the formulation of the HadCM3 sea-ice model and provide details of the dynamic and thermodynamic components. The mean fields of sea ice used in the validation as determined from satellite passive microwave imagery are discussed in section 3. The broadscale and regional fields of sea-ice extent are examined in section 4 before specific shortcomings are considered in section 5. Plans for the development of the model's sea-ice representation are outlined in section 6 .

\section{HadCM3 AND THE SEA-ICE FORMULATION USED IN THE MODEL}

HadCM3 has a horizontal resolution of $2.5^{\circ}$ latitude by $3.75^{\circ}$ longitude for the atmospheric component and $1.25^{\circ}$ by $1.25^{\circ}$ in the oceans. There are 19 levels in the atmosphere and 20 vertical levels in the ocean. The oceanic and atmospheric components are coupled once a day and the ocean model (which includes the sea-ice model) has a time-step of $1 \mathrm{~h}$. The formulation and performance of the ocean model is covered in Gordon and others (2000), while the atmospheric model is dealt with by Pope and others (2000).

The sea-ice component of the model is based on Semtner's zero-layer thermodynamics (Semtner, 1976), with a leads parameterization based on that of Hibler (1979) and simple ice advection (Bryan and others, 1975). The sea ice is represented by ice concentration, ice thickness and snow thickness on the resolution of the ocean model. For the purpose of calculating heat flux through the ice, the ice and snow layer are considered to be a single layer, with an effective thermal conductivity reflecting the proportion of ice to snow and their different conductivities. Separate heat fluxes are calculated over the leads and ice-covered portions of a gridbox. The ice surface temperature, conductive heat flux through the ice, surface albedo and atmospheric heat and water fluxes are calculated within the atmospheric model, with a temperature-dependent ice/snow albedo and a surface heat capacity parameterization (Gordon and Bottomley, 1984). Atmospheric wind stresses are computed taking account of the roughness length and ice concentration, and this stress is communicated through the ice to the ocean. There is also a parameterization of white-ice formation, where the weight of snow on a floe depresses the ice surface below the level of the water and the sea water infiltrates the snow and freezes. This process is believed to be especially important in the Antarctic. The ice is advected with the ocean surface current, except in regions of convergent flow and thick ice $(>4 \mathrm{~m})$, where the ice is restricted from flowing up a gradient of ice thickness (Cattle and Crossley, 1995).

\section{VALIDATION DATA}

Comparing sea-ice extent in model output with remotesensing observations presents a number of problems because of the very different horizontal resolutions used by the models and satellite instruments, and the problems of defining the sea-ice edge. In addition, both the models and satellite sensors have problems around the Antarctic coast where model gridboxes or satellite fields of view are partly ice and partly land. Therefore the question of the land-sea mask to be used must be taken into account.

For validation in this study we have used the fields of monthly mean sea-ice extent and concentration produced by the Ocean Modelling Branch of the Environmental Modelling Center at the U.S. National Centers for Environmental Prediction. These fields have been produced for the period 1979-present and were based on data from the Special Sensor Microwave/Imager (SSM/I) on the Defense Meteorological Satellite Program (DMSP) satellites. The processing algorithm used to convert the brightness temperatures into ice-extent and ice-concentration values was the NASA seaice algorithm working-group procedure (Cavalieri, 1992). Comparisons of the satellite-derived ice concentrations against high-resolution Landsat and synthetic aperture radar imagery suggest that the concentration values are accurate to within 1-2\% (Martin and others, 1987; Steffen and Schweiger, 1991). In the paper we take the ice extent to be the area bounded by the $15 \%$ ice concentration.

\section{SEA-ICE EXTENT}

The mean sea-ice amounts for each month of the year as determined from the satellite data and from the 100 years of HadCM3 data are shown in Figure 2. It can be seen that the model has an overall representation of the seasonal cycle, but except for September-November it always has less sea ice than is observed by the satellite. Over the year as a whole, the satellite data give a mean extent for the whole of the Antarctic of $1.26 \times 10^{7} \mathrm{~km}^{2}$ of ice, and the model $1.14 \times 10^{7} \mathrm{~km}^{2}$. The model therefore had about $91 \%$ of the sea ice that is estimated from the satellite data. At the sea-ice minimum during February there is too little ice (59\%) in the model, and this underestimation persists and increases in March 


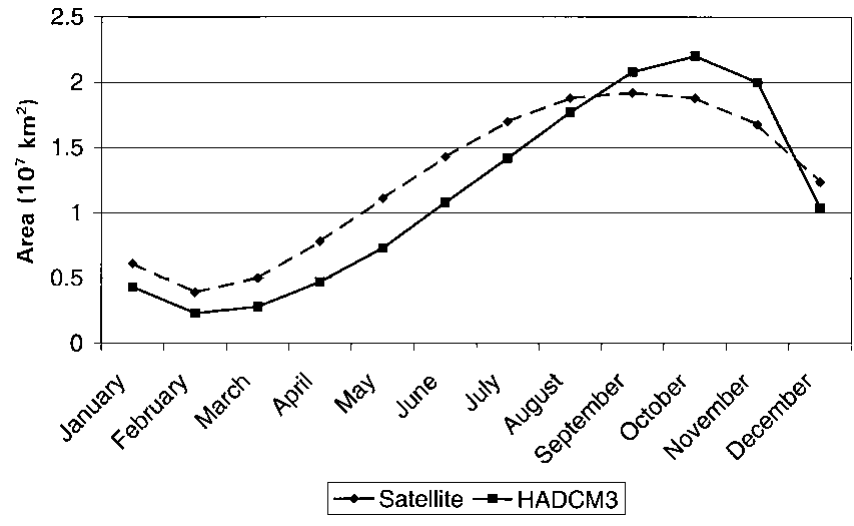

Fig. 2. The mean integrated extent of sea-ice bounded by the $15 \%$ concentration line in the model and satellite data for each month of the year.

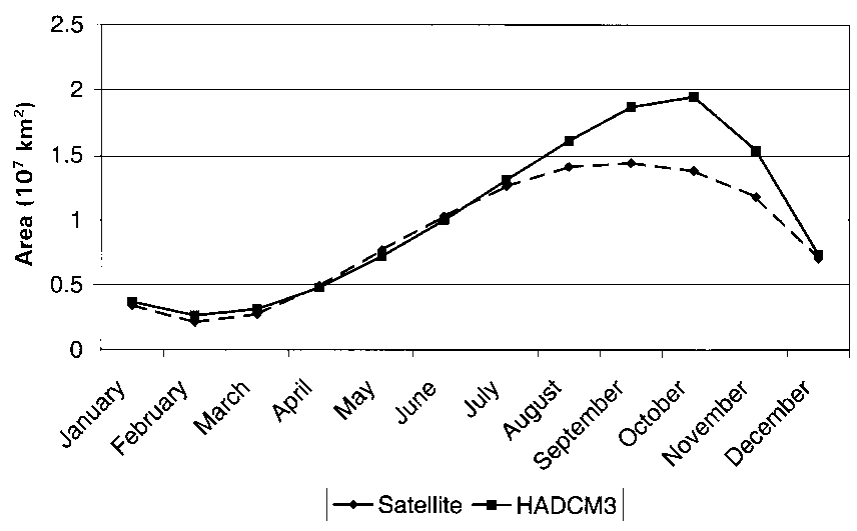

Fig. 3. The mean integrated ice area bounded by the $15 \%$ concentration line in the model and satellite data for each month of the year.

when the model has only $56 \%$ of the ice indicated by the satellite data. From April until August the model underestimation of ice coverage gradually reduces until the model actually has more ice than the satellite data in SeptemberNovember. The overestimation of sea ice is greatest in November, when the model has $19 \%$ more ice coverage than the satellite data. Between November and February, however, there is a rapid decrease in the sea-ice extent in the model, with model ice retreating at a faster rate than is suggested by the satellite data.

It is possible using both the satellite and model sea-ice concentration data to compute the actual area covered by ice rather than just to integrate the area bounded by the $15 \%$ ice-concentration limit. These data are shown in Figure 3 for each month of the year. It can be seen that the model fits the seasonal cycle of satellite-derived ice area in summer, but over the winter months (July-December) it significantly overestimates it. This problem will be examined in more detail below.

The spatial variability of the sea ice in the model is now examined through a comparison with the mean sea-ice concentration fields as derived from the satellite data. Figure 4 shows both the model and satellite data for September close to the time of the observed sea-ice maximum in late winter. In Figure 4a the model sea-ice edge taken as the $15 \%$ ice concentration is shown as a dashed line. Around the continent the regional detail of the ice extent in the model is, not sur-
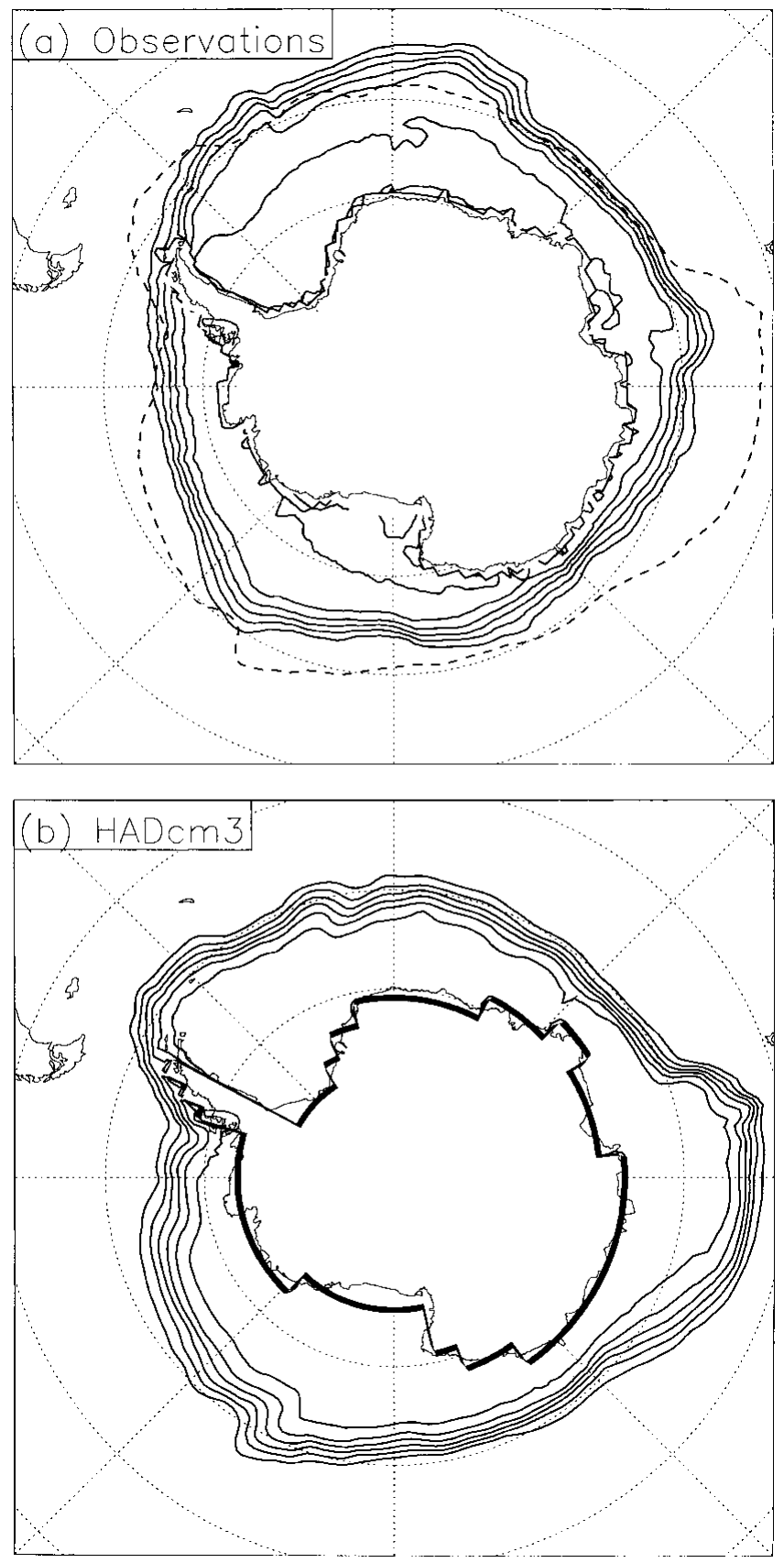

Fig. 4. Mean ice concentrations during September as determined from ( a) the satellite data and ( $b$ ) the HadCM3 run. The model ice edge (15\%) concentration is shown in (a) as a dashed line. Contours are drawn at 15, 30, 45, 60, 75 and $100 \%$ ice concentrations.

prisingly, deficient, with areas where the extent is greater and less than the satellite data. The largest difference is close to $90^{\circ} \mathrm{E}$ where a northward extension of ice is present that extends $4-5^{\circ}$ north of the satellite ice edge. Along the coast of East Antarctica from about $135^{\circ} \mathrm{E}$ to almost $90^{\circ} \mathrm{W}$ the model has more ice than the satellite data, but the difference is generally only about $1-2^{\circ}$. The model has much less ice than the satellite dataset near the Greenwich meridian and across the sector $30^{\circ} \mathrm{W}$ to $30^{\circ} \mathrm{E}$ where the differences are up to about $3^{\circ}$ of latitude. The model also has a lack of sea ice to the west of the Antarctic Peninsula. The other major difference between the two datasets is with the sea-ice concentrations. The model concentrations within the pack are higher than in the satellite data and are $>90 \%$ from the coast to close to the sea-ice edge. In the satellite data such high concen- 

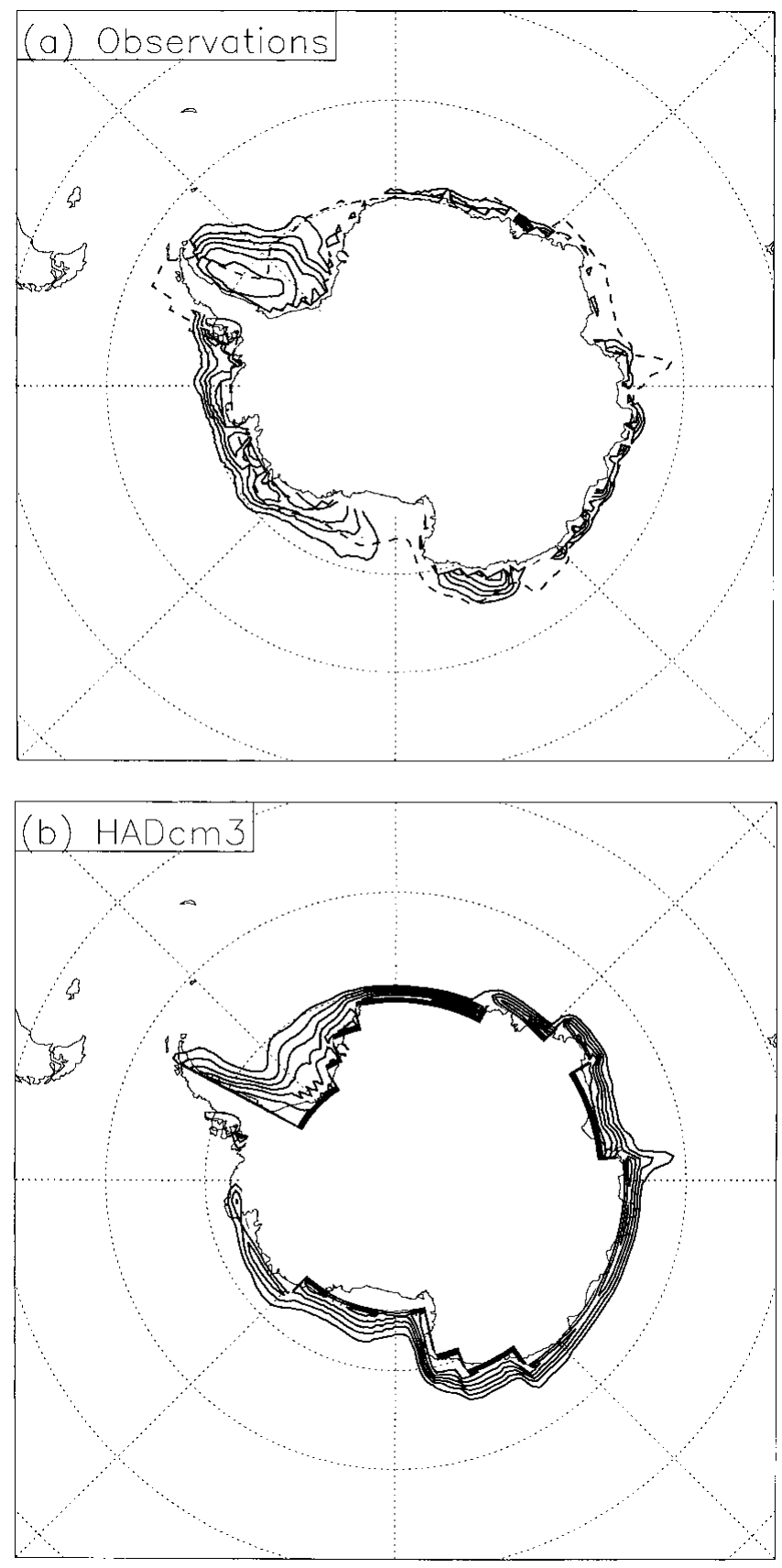

Fig. 5. Mean ice concentrations during February as determined from ( $a$ ) the satellite data and $(b)$ the HadCM3 run. The model ice-edge $(15 \%)$ concentration is shown in (a) as a dashed line. Contours are drawn at 15, 30, 45, 60, 75 and $100 \%$ ice concentrations.

tration values are limited to the Weddell Sea (where extensive multi-year sea ice is present), just east of the Greenwich meridian and in the Ross Sea. However, the determination of high ice concentrations from passive microwave data is difficult, and we cannot be certain whether the concentrations determined from the satellite data are correct here or elsewhere.

Similar plots of model and satellite-derived sea-ice extents are presented for February, near the sea-ice minimum, in Figure 5. The general underestimation of sea-ice extent that was apparent in Figure 2 can be seen to be a result largely of a lack of ice around the Antarctic Peninsula, with virtually no ice being present in the model over the Bellingshausen Sea and far too little ice over the western Weddell Sea. Around the coast of East Antarctica the model and satellite ice extents are fairly
Table 1. The five ocean sectors used in this study

\begin{tabular}{lrr}
\hline Sector & Western limit & Eastern limit \\
& & \\
\hline Indian Ocean & $20^{\circ} \mathrm{E}$ & $90^{\circ} \mathrm{E}$ \\
Western Pacific Ocean & $90^{\circ} \mathrm{E}$ & $160^{\circ} \mathrm{E}$ \\
Ross Sea & $160^{\circ} \mathrm{E}$ & $130^{\circ} \mathrm{W}$ \\
Bellingshausen-Amundsen Sea & $130^{\circ} \mathrm{W}$ & $60^{\circ} \mathrm{W}$ \\
Weddell Sea & $60^{\circ} \mathrm{W}$ & $20^{\circ} \mathrm{E}$ \\
& & \\
\hline
\end{tabular}
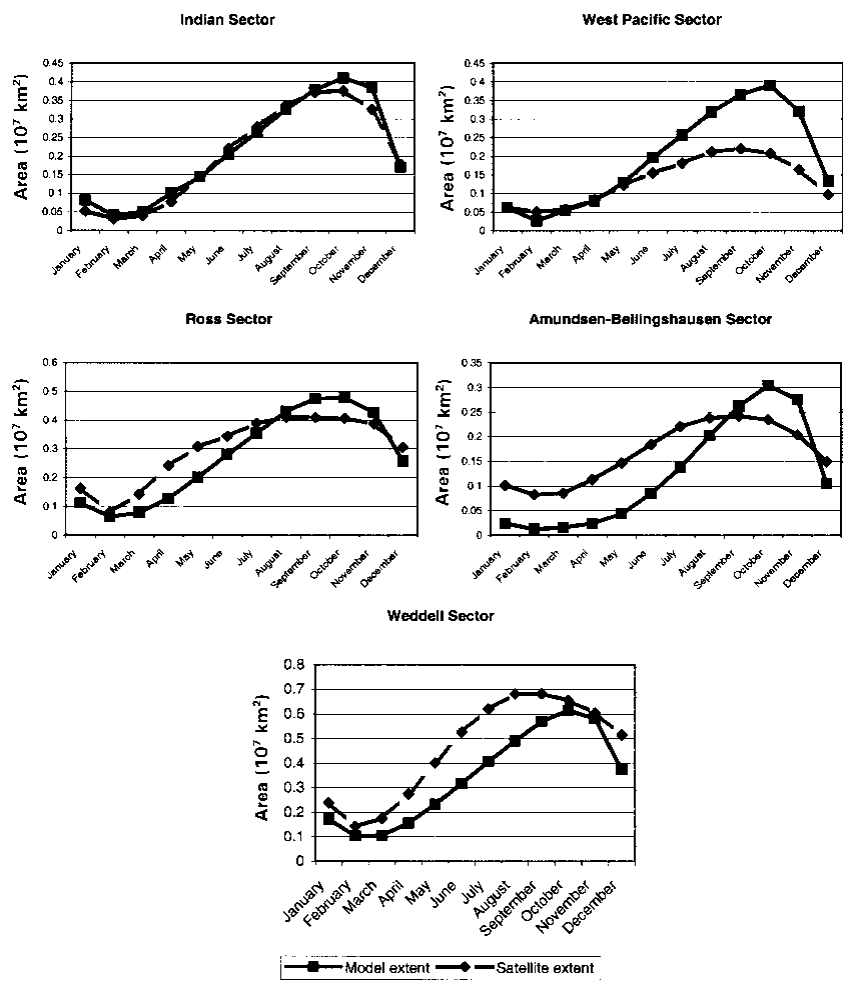

Fig. 6. The mean integrated extent of sea ice bounded by the $15 \%$ concentration line in the model and satellite data for each month of the year for the five areas shown in Figure 1.

similar, with only a slight underestimation of ice. Close to $90^{\circ} \mathrm{E}$ there is a narrow northward-extending tongue of sea ice close to where the major positive anomaly is present in September. A detailed analysis of this feature is presented below.

The regional variations in the model ice extent can be appreciated further from the figure indicating the model and satellite ice extents for five sectors around the Antarctic shown in Figure 6. The sectors used are shown in Figure 1 and identified in Table 1 and are those used by Gloersen and others (1992) in their study of sea-ice variability based on passive microwave imagery. From Figure 6 the model appears to perform best in the Indian sector, where there are only small differences between the two datasets throughout the year. As can be seen in Figure 4, however, the good performance near the ice maximum masks an overestimation of the ice near $90^{\circ} \mathrm{E}$ and an underestimation further west. The most pronounced effects of the excess of ice near $90^{\circ} \mathrm{E}$ are felt in the Western Pacific sector where there is almost double the amount of ice observed by the satellite during the SeptemberOctober period. However, as the ice tongue disappears towards the February minimum the model and satellite data have comparable amounts of ice. The reasons for the presence of the ice tongue near $90^{\circ} \mathrm{E}$ are discussed below. 
The extent data for the Ross Sea sector are very similar to those for the whole of the Antarctic, with the ice advance being too slow at the start of the winter and the retreat too fast at the start of the summer. During the sea-ice advance the model has the greatest underestimation of sea ice close to $150^{\circ} \mathrm{W}$ and this persists until August, being followed by an overestimation close to the same longitude.

The model performance is poorest in comparison to the satellite observations in the Amundsen-Bellingshausen sector, where there is virtually no sea ice during the JanuaryMarch period and the growth rate is too slow during April and May. However, the sea ice rapidly advances from June to October, exceeding the amount of sea ice observed by the satellite in September. In October the northern limit of the sea ice in the model is approximately in agreement with the satellite data at about $70^{\circ} \mathrm{W}$, but extends too far north to the east and west of this longitude. To the west and north of the Antarctic Peninsula there is far too much ice in the model, and north of the tip of the Peninsula the ice extends about $2^{\circ}$ of latitude (about $200 \mathrm{~km}$ ) further north than in reality. There are also significant problems in the model ice extent in the Weddell Sea in winter. During the late summer the multi-year sea-ice over the western Weddell Sea is reasonably well simulated, with a realistic northern ice edge. However, there is too little ice over the northeastern part of the Weddell Sea, although conditions are reasonable just north of the Ronne Ice Shelf. These conditions prevail until about July, after which time the ice starts to push too far north over the western Weddell Sea while still having too little ice over the eastern part of the area. By November there is a realistic ice edge over the eastern Weddell Sea, but the excessively northerly ice edge north of the Peninsula means that there is too much ice overall in this sector.

\section{GAUSES OF REGIONAL DEFIGIENGIES IN THE MODEL SIMULATION OF SEA ICE}

In this section we examine in detail the factors that are responsible for the differences between the satellite and model sea-ice extents in a number of areas around the continent. Errors in the model sea-ice extent can be caused by a number of factors, including the following:

1. Poorly represented ice rheology (the terms in the ice momentum equation resulting from stresses within the pack) in the model.

2. Biases in the model wind field.

3. Errors in the ocean currents that would incorrectly advect sea ice into or out of an area.

4. Errors in the ocean temperatures that would cause too much (too little) ice to form/melt if the temperatures were too low (high).

5. Errors in the near-surface air temperatures caused by problems in the model physical parameterization schemes or by errors in the atmospheric flow. It should be noted that errors in the atmospheric flow itself only indirectly affect the sea ice since it is advected only by the ocean currents. However, errors in the meridional flow can have a significant effect on the near-surface temperature fields, with small errors in temperature leading to under- or overestimations of the sea-ice extent.
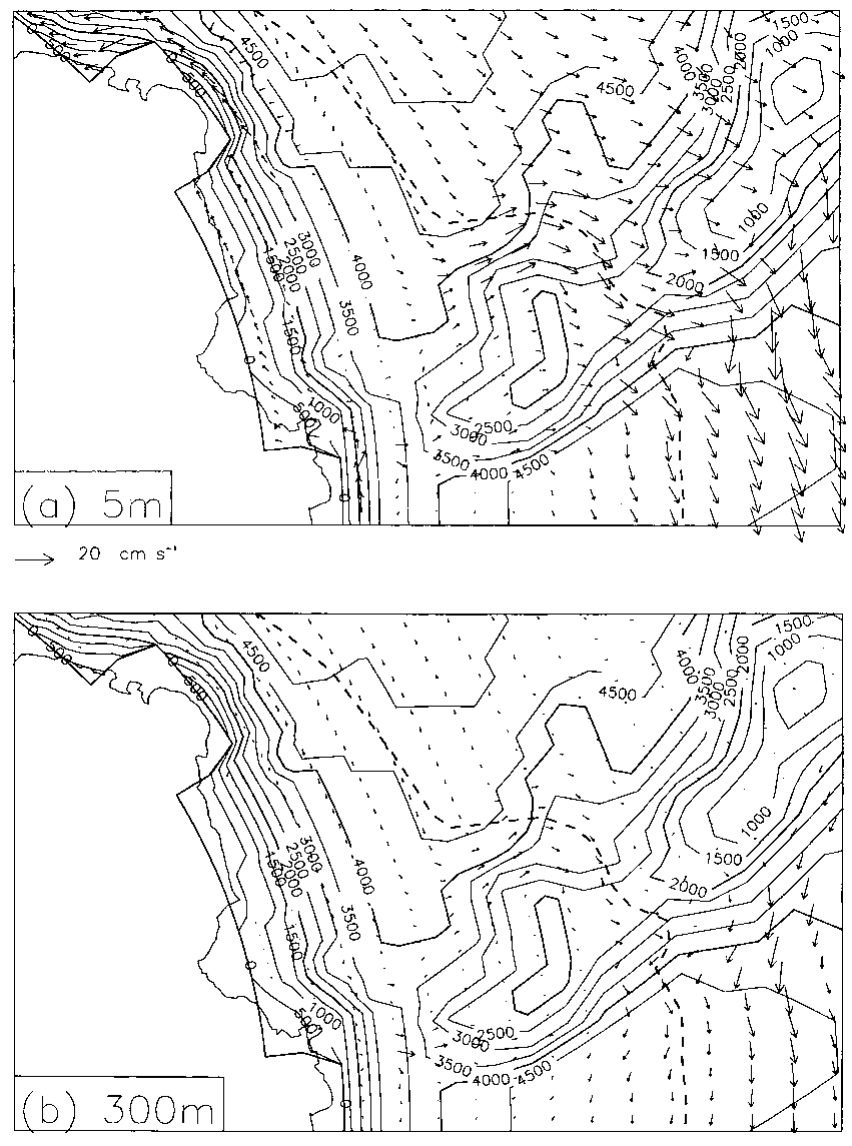

$\rightarrow 20 \mathrm{~cm} \mathrm{~s}^{-1}$

Fig. 7. The model bathymetry for East Antarctica (solid lines) and (a) $5 \mathrm{~m}$ and (b) $300 \mathrm{~m}$ ocean currents shown as vectors. The model ice edge is indicated by a dashed line. The data are a mean of June-August conditions.

\subsection{The ice tongue near $90^{\circ} \mathrm{E}$}

A small remnant of this problem is present in the mean February ice extent (Fig. 5), but the feature grows rapidly throughout the winter months to reach a maximum in September-October (Fig. 4) when the model ice edge is about $4^{\circ}$ of latitude $(400 \mathrm{~km})$ too far north. An examination of the model ocean currents suggests that the cause is too strong a current towards the north around $70-80^{\circ} \mathrm{E}$. This can be appreciated from the mean June-August ocean currents at the 5 and $300 \mathrm{~m}$ depths in the vicinity of the ice tongue shown in Figure 7. Here the currents are shown as vectors superimposed on the field of ocean depth. Although the ocean currents are towards the east or north-northeast in the sector from $45^{\circ} \mathrm{E}$ to about $70^{\circ} \mathrm{E}$, the flow changes rapidly to one to the north just to the west of the Kerguelen Plateau. A comparison of the flow and the ocean bathymetry in the model with that in the Fine Resolution Antarctic Model (FRAM) atlas of the Southern Ocean (Webb and others, 1991) suggests that the bathymetry used in HadCM3 is broadly correct, with the ocean depth over the southern part of the plateau being about $2000 \mathrm{~m}$. However, in the runs of the much higher-resolution FRAM model the flow is deflected to the south of the Kerguelen Plateau and then turns to the north just east of the plateau, which agrees with the available observations. To the west of the plateau the flow in FRAM is more easterly than in HadCM3, so it may be that this more southerly component in the model results in the lack of a strong current around the southern part of the plateau. Alternatively, 
it may be that the AOGCM is sensitive to slight changes in the bathymetry around the plateau, giving markedly different flow to the south or north of the plateau if only slight changes are made to the bathymetry. We plan to test these hypotheses by running HadCM3 with small changes in the bathymetry. It should be noted that a run of HadCM3 with freedrift (discussed below) still has the above problem around Kerguelen, suggesting that the bathymetry is the primary cause, rather than the atmospheric forcing.

\subsection{The lack of sea ice to the west of the Antarctic Peninsula}

Throughout the year there is too little sea ice in the Bellingshausen Sea, this being most obvious during the summer months when there is virtually no ice cover at all over the region. Even during June, when the satellite data indicate that the ice is advancing northwards, the model still has no ice in the very southeasternmost part of the Bellingshausen Sea. However, as seen in Figure 6 for the AmundsenBellingshausen Sea sector, the model has too much sea ice during September-October compared to the satellite data. This is because there is an excess of ice in the sector 90$130^{\circ} \mathrm{W}$, while just to the west of the Peninsula the model still has too little ice.

An examination of the pressure at mean sea-level fields suggests that the model has surface pressures too deep over the Amundsen-Bellingshausen Sea, with a maximum difference, when compared to the European Centre for Mediumrange Weather Forecasts (ECMWF) re-analysis (ERA) data, close to $60^{\circ} \mathrm{S}, 120^{\circ} \mathrm{W}$. This results in near- surface winds that have too strong a northerly component when compared to the ERA data, resulting in too much warm air advection into the Bellingshausen Sea. Since the model near-surface temperatures are very strongly influenced by the sea-ice extent, the HadCM3 and ERA temperatures (not shown) are, not surprisingly, very different. However, the excessively strong flow of mild mid-latitude air into the Bellingshausen Sea is thought to be responsible for most of the slow development of sea ice during the winter season and the rapid melt of the ice during the early summer.

The ocean currents in HadCM3 tend to be quite light (around 2-3 $\mathrm{cm} \mathrm{s}^{-1}$ ) and towards the south over the Bellingshausen Sea. This is in contrast to the currents in the FRAM atlas, which are generally $5-10 \mathrm{~cm} \mathrm{~s}^{-1}$ towards the north-northeast. However, there are few observational data on ocean currents in the Bellingshausen Sea, and it is not known to what extent the FRAM currents here can be relied upon. In addition, the erroneous northerly atmospheric flow in the area (related to corresponding errors in the model's mean sea-level pressure field) will influence the model's ocean currents.

\subsection{Ice conditions in the Weddell Sea}

As indicated above, in the model the Weddell Sea is characterized by too little sea ice over the eastern part of the region, especially from the sea-ice minimum to about September. This is coupled with increasingly too much ice just to the east of the Antarctic Peninsula between about April and November, and then disappearing by January. A comparison of the HadCM3 atmospheric fields with the ERA data suggests that the climate model has surface pressures that are slightly too high over the Weddell Sea, tending to force a slightly more anticlockwise circulation over the area. However, this would work against the establishment of the errors observed. There is, however, an opposing and stronger source of error in the model, stemming from problems with the model's simulation of the oceanic flow and the handling of the multi-year sea ice, which is such a feature of the western Weddell Sea. A comparison of the model and FRAM ocean currents through the Drake Passage and South Atlantic suggests that the currents in the model are too weak just north of the sea ice in the Weddell Sea $\left(12-15 \mathrm{~cm} \mathrm{~s}^{-1}\right.$ compared to $20-30 \mathrm{~cm} \mathrm{~s}^{-1}$ in the higher-resolution FRAM model). This may well allow the model ice to advance to an erroneously northerly position and explain the tongue of ice to the east of the Peninsula that is apparent in Figure 4. Since there is a clockwise gyre in the Weddell Sea, if ice flow over the western Weddell Sea is too strong towards the north then this may well force the compensating flow over the eastern Weddell Sea to be too strong from the north, which overwhelms the weaker anticyclonic error in the atmospheric forcing.

Given the simple nature of the sea-ice dynamics scheme, it is not surprising that the ice is poorly simulated over the western Weddell Sea. Here there is a large area of multi-year ice with convergence and extensive rafting where the handling of the ice interactions is clearly important. As discussed below, the testing of improved sea-ice dynamics schemes within HadCM3 is underway and these should give insight into the issues outlined above.

\subsection{The delayed peak in the model's sea-ice maximum}

Although the timing of the sea-ice minimum in February is well handled by the model, along with the growth rate throughout most of the winter, a problem is the fact that the largest extent of ice is found about a month too late in October. This problem is found around the whole of the Antarctic and there are no regional variations in this lag. An examination of the model temperatures just north of the sea-ice edge does not indicate any cold bias in the model during this month, which could cause sea ice to continue forming. The lateness of the peak could be a result of the lack of sea ice near the minimum, although around some parts of East Antarctica there was too much ice in February, and in these locations the ice continued to extend between September and October. Further possible reasons for this problem are the fact that atmospheric-forcing data are only provided on a daily basis (by taking the mean over the whole day's atmospheric forcing) (Hanesiak and others, 1999); limitations in the modelling of the thermodynamics; and the simple representation of ice rheology and forcing. The importance of these various factors should become clear once the runs with improved dynamics described below are carried out.

\section{DISGUSSION AND FUTURE WORK}

From the above it will be appreciated that there are a number of deficiencies in the HadCM3 model's simulation of sea ice around Antarctica. However, understanding the reasons for the differences from the observational datasets available is not easy and requires the development of good diagnostic tools and the ability to carry out fairly long runs with slightly modified conditions. Such runs are planned to investigate the problems in the oceanic flow around the Kerguelen Plateau. A further difficulty in correcting the problems is that changes 
in one part of the model can have a major impact on other components in the ocean or atmosphere. In addition, the deficiencies observed in the sea-ice representation may be the result of failings in the atmospheric or oceanic simulation and cannot necessarily be corrected by changes in the sea-ice model. For example, the lack of sea ice in the Bellingshausen Sea seems to be related to the simulation of atmospheric systems over the Amundsen Sea, rather than any local factors to the west of the Peninsula.

Further insight into the problems will also be gained once new sea-ice dynamics schemes are tested over the coming months. A freedrift scheme has been implemented, which will allow the wind field to have a direct effect on the sea-ice motion. In addition, viscous-plastic and elasticviscous-plastic rheologies are also being tested, which will hopefully handle the stresses within the sea ice in a much more realistic fashion and give improved handling of the ice in areas such as the western Weddell Sea. These schemes should improve the simulation of ice concentrations within the pack, which seem to be too high, through the better handling of small-scale dynamical effects (e.g. rafting of ice). The excessively high concentrations may also be a result of using only the ocean currents to advect the sea ice, and the direct use of the near-surface winds should help to give a more divergent flow, which may reduce the concentrations. Once a four-way intercomparison of sea-ice simulation can be carried out (comparing the ocean drift, freedrift, viscous-plastic and elastic-viscous-plastic runs of the model with satellite data), further insight into the ways to further improve the model in the Antarctic should be obtained.

\section{ACKNOWLEDGEMENT}

This work was funded by the European Union under the Framework IV Programme, contract number ENV4CT97-0415.

\section{REFERENCES}

Bryan, K. 1969. Climate and the ocean circulation. III. The ocean model. Mon. Weather Rev., 97(11), 806-827.

Bryan, K., S. Manabe and R. C. Packanowski. 1975. A global ocean- atmosphere climate model. II. The oceanic circulation. F. Phys. Oceanogr., 5(1), 30-46.

Cattle, H. and J. Crossley. 1995. Modelling Arctic climate change. Philos. Trans. R. Soc. London, Ser. A, 352(1699), 201-213.

Cavalieri, D. J. 1992. Sea ice algorithm in NASA sea-ice validation program for the Defense Meteorological Satellite Program Special Sensor Microwave Imager. Final report. Greenbelt, MD, National Aeronautics and Space Administration. Goddard Space Flight Center. (NASA TM-1004559.)

Gloersen, P., W. J. Campbell, D. J. Cavalieri, J. C. Comiso, C. L. Parkinson and H.J. Zwally. 1992. Arctic and Antarctic sea-ice, 1978-1987: satellite passive-microwave observations and analysis. Washington, DC, National Aeronautics and Space Administration. (NASA SP-511.)

Gordon, C. and M. Bottomley. 1984. A scheme for incorporating the thermodynamic sea-ice model into a coupled ocean-atmosphere model. Bracknell, Meteorological Office. (Dynamical Climatology Technical Note 1.)

Gordon, C. and 7 others. 2000. The simulation of SST, sea ice extents and ocean heat transports in a version of the Hadley Centre coupled model without flux adjustments. Climate Dyn., 16(2-3), 147-168.

Hanesiak, J. M., D. G. Barber and G. M. Flato. 1999. The role of diurnal processes in the seasonal evolution of sea-ice and its snow cover. F. Geophys. Res., 104(C6), 13,593-13,603.

Hibler, W. D., III. 1979. A dynamic thermodynamic sea ice model. F. Phys. Oceanogr., 9(7), 815-846.

Johns, T. C. and 7 others. 1997. The second Hadley Centre coupled oceanatmosphere GCM: model description, spinup and validation. Climate Dyn., 13(2), 103-134.

Martin, S., B. Holt, D. J. Cavalieri and V. Squire. 1987. Shuttle imaging radar B (SIR-B) Weddell Sea ice observations: a comparison of SIR-B and scanning multichannel microwave radiometer ice concentrations. 7. Geophys. Res., 92(C7), 7173-7179/7223-7224.

Maykut, G. A. 1978. Energy exchange over young sea-ice in the central Arctic. 7. Geophys. Res., 83(C7), 3646-3658.

Mitchell, J. F. and T. S. Hills. 1986. Sea-ice and the Antarctic winter circulation: a numerical experiment. Q. F. R. Meteorol. Soc., 112(4), 953-969.

Murphy, J. M. 1995. Transient response of the Hadley Centre coupled ocean- atmosphere model to increasing carbon dioxide. Part I. Control climate and flux adjustment. 7. Climate, 8(1), 36-56.

Pope, V. D., M. L. Gallani, P. R. Rowntree and R. A. Stratton. 2000. The impact of new physical parameterizations in the Hadley Centre climate model: HadAM3. Climate Dyn., 16(2-3), 123-146.

Semtner, A. J., Jr. 1976. A model for the thermodynamic growth of sea-ice in numerical investigations of climate. F. Phys. Oceanogr., 6 (5), 379-389.

Steffen, K. and A. Schweiger. 1991. NASA team algorithm for sea-ice concentration retrieval from Defense Meteorological Satellite Program special sensor microwave imager: comparison with Landsat satellite imagery. F. Geophys. Res., 96 (C12), 21,971-21,987.

Webb, D. J., P. D. Killworth, A. C. Coward and S. R. Thompson, eds. 1991. The FRAM atlas of the Southern Ocean. Swindon, Natural Environment Research Council.

Wood, R. A., A. B. Keen, J. F. B. Mitchell and J. M. Gregory. 1999. Changing spatial structure of the thermohaline circulation in response to atmospheric $\mathrm{CO}_{2}$ forcing in a climate model. Nature, 399(6736), 572-575. 